\title{
Optimization of Cellulose-Based Hydrogel Synthesis Using Response Surface Methodology
}

\author{
Suk-Fun Chin ${ }^{1, *}$, Shu-Jun Jong ${ }^{1}$, Yit-Juan Yeo ${ }^{1}$ \\ 1 Faculty of Resource Science and Technology, Universiti Malaysia Sarawak 94300, Kota Samarahan, Sarawak, Malaysia; \\ * Correspondence: sfchin@unimas.my (S.F.C);
}

Scopus Author ID 16644797900

Received: 2.09.2021; Revised: 3.11.2021; Accepted: 6.11.2021; Published: 24.11.2021

\begin{abstract}
Synthesis parameters have a significant effect on the properties of cellulose hydrogel. This study aimed to investigate the effects of synthesis parameters, e.g., the cellulose and crosslinkers concentration, on the hydrogels' swelling ratio under both heating and freezing gelation conditions, respectively. Cellulose hydrogels were prepared from wastepaper by the chemical crosslinking method by using epichlorohydrin ECH as a crosslinker. The effects of the synthesis parameters were compared and optimized by response surface methodology (RSM). Synthesized cellulose-based hydrogels under optimized conditions demonstrated an excellent swelling ratio of around $2800 \%$. The optimum swelling ratio of $2467.72 \%$ was achieved from the experiment under the heating gelation condition. Thus the synthesized cellulose hydrogels are promising water-saving materials or controlled-release fertilizer carriers for sustainable horticultural and agricultural applications.
\end{abstract}

Keywords: cellulose-based hydrogel; swelling property; response surface methodology (RSM); sustainable agriculture.

(C) 2021 by the authors. This article is an open-access article distributed under the terms and conditions of the Creative Commons Attribution (CC BY) license (https://creativecommons.org/licenses/by/4.0/).

\section{Introduction}

Hydrogels are the 3-dimensional crosslinked network structure of hydrophilic polymers with abundant hydrophilic functional groups that can be easily linked with a large number of water molecules. They can retain a large amount of water and swell without dissolving in the water; as a result, hydrogels have high water absorbency [1-4]. Cellulose is one of the favorable precursor materials for the preparation of hydrogel due to its biocompatibility, low cost, renewability, abundance, biodegradability, and non-toxicity [5-7]. Cellulose has been explored by researchers for the fabrication of cellulose-based hydrogel, nanoparticles, and aerogel for various biomedical and technological applications [8-10]. Cellulose-based hydrogels can be prepared from various cellulose-containing agricultural wastes and wastepaper. The utilization of these agricultural cellulosic wastes as the precursor materials for the synthesis of hydrogels enables the conversion of cellulosic wastes into value-added products as an alternative to generating wealth from wastes [11].

Due to the ease of manipulation of their properties and chemical compositions, hydrogels have been extensively studied for application in various fields. One of the most studied applications of hydrogels is in biomedical applications, such as drug delivery [12], wound dressings [13,14], and tissue engineering[15]. Recently, studies reported evaluating cellulose-based hydrogels as a water reservoir and controlled release fertilizer carriers in horticulture and agriculture[16,17]. 
Macroscopic properties of the hydrogels can be tailored for targeted applications by manipulating the synthesis parameters [18]. However, proper and precise control of the hydrogel's macroscopic properties only can be achieved by understanding the relationship of the synthesis parameters with the macroscopic properties such as swelling properties. Among the synthesis parameters that can affect the swelling properties of the cellulose-based hydrogel include the concentration of crosslinker, cellulose concentrations, and gelation conditions. In this study, the effects of the concentration of cellulose and the crosslinker (epichlorohydrin, $\mathrm{ECH}$ ) and gelation conditions (freezing and heating) on the swelling ratio were evaluated and optimized by both experimental and Response Surface Methodology (RSM).

\section{Materials and Methods}

\subsection{Materials and reagents.}

The wastepaper was collected from the Faculty of Resource and Science Technology office, Universiti Malaysia Sarawak. Urea was procured from J. T. Baker (Philipsburg, United States of America). Absolute ethanol was supplied by HmbG® Chemicals (Germany). Sodium hydroxide $(\mathrm{NaOH})$ was purchased from QREC (ASIA) (Selangor, Malaysia). Thiourea was supplied by Bendosen. Sodium chlorite $\left(\mathrm{NaClO}_{2}\right)$ was procured from ACROS ORGANICS (New Jersey, United States of America) and epichlorohydrin (ECH) from Aldrich (Wisconsin, United States of America). All chemicals were used without further purification. All the chemicals were used without further purification. Ultrapure water $\left(\sim 18.2 \mathrm{M} \Omega . \mathrm{cm}, 25^{\circ} \mathrm{C}\right)$ was formed from the Water Purifying System (ELGA, Model Ultra Genetic)

\subsection{Extraction of the cellulose fibers.}

The extraction of the cellulose fibers from the wastepaper was based on the methods previously reported $[19,20]$. The wastepaper was cut into small pieces and grounded to powder. Then, the sample with a mass of $10 \mathrm{~g}$ was soaked in $12 \mathrm{wt} . \% \mathrm{NaOH}$ solution for 24 hours to remove the ink particles and hemicelluloses [21]. After the cellulose fiber had been pretreated, $\mathrm{HCl}$ solution ( $3 \mathrm{wt} \%$ ) was added to it to remove the lignin residuals at $80^{\circ} \mathrm{C}$ for 2 hours, and the cellulose fibers were rinsed with the ultrapure water and dried in an oven until a constant weight of cellulose fibers was obtained [19-21].

\subsection{Dissolution and regeneration of cellulose fibers.}

Three different masses of isolated cellulose fibers were dissolved in 8:6.5:8 $(\% \mathrm{w} / \mathrm{v})$ $\mathrm{NaOH} /$ thiourea/urea (NTU) and stirred regularly for 15 minutes to obtain cellulose solution with concentrations of $3 \%, 4 \%$, and $5 \%(\mathrm{w} / \mathrm{v})$. Then, all the samples were frozen in a freezer at $-20^{\circ} \mathrm{C}$ for 24 hours and after the solid frozen mass had formed, and later the frozen mass was thawed at room temperature to obtain clear cellulose solutions [19].

After all the cellulose fibers had fully dissolved in NTU solvent, the cellulose fibers were regenerated to break down the intermolecular bonds formed during the dissolution process and reform the hydrogen bonds [22]. The cellulose solution was added dropwise into the absolute ethanol, which was stirred continuously at a constant rate with the ratio of 1:2 of cellulose: ethanol. The mixtures were further stirred for another 30 minutes after the cellulose solution was added completely. The mixtures were filtered and washed by the absolute ethanol 
and distilled water three times respectively before the regenerated cellulose was dried in the oven with the temperature of $60^{\circ} \mathrm{C}$ for 12 hours.

\subsection{Preparation of the cellulose hydrogels.}

The cellulose hydrogels were prepared using two different methods, namely the freezing and heating methods. (2010) [23]. First, 8:6.5:8 (\% w/v) NaOH/thiourea/urea (NTU) were mixed to produce $100 \mathrm{~mL}$ of NTU aqueous solution. Then, the different weight of the regenerated cellulose was added into the NTU solution to produce the cellulose with various concentrations. Each of the cellulose solutions was stirred for 15 minutes. The ECH crosslinker with a volume range from $100 \mu \mathrm{L}(2 \%)$ to $500 \mu \mathrm{L}(10 \%)$ was added dropwise into each cellulose solution.

The mixtures were frozen for 20 hours with a constant temperature of $-20^{\circ} \mathrm{C}$ and thawed at room temperature until the mixtures were turned into solid form in the freezing method to form hydrogels. For the heating gelation method, the mixtures were heated in the water bath at $50^{\circ} \mathrm{C}$ for 20 hours, and the hydrogels formed were washed with the excess water to remove the NTU solutions.

\subsection{Characterization of the cellulose hydrogels.}

\subsubsection{Scanning Electron Microscope.}

The morphology of cellulose hydrogel was observed using a scanning electron microscope (SEM) (JEOL JSM 6390LA). The samples were dropped on stainless steel plates, dried at room temperature, and then coated with a layer of platinum using an Auto Fine Coater (JEOL JFC-1600).

\subsubsection{Swelling ratio.}

For measuring the swelling ratio, the hydrogel samples were soaked in ultrapure water for a minimum of 24 hours at room temperature. Then, the swollen hydrogel was taken out and gently swabbed with tissue paper before it was weighted. The swollen hydrogel was placed into the oven, dried at $105{ }^{\circ} \mathrm{C}$ for at least 12 hours, and was taken out after constant weight was achieved. The swelling ratio was evaluated by using equation (1).

$$
\text { Swelling ratio }(S R \%)=\frac{W_{S}}{W_{D}} \times 100 \%
$$

in which the symbol of Ws is the weight of the swollen hydrogels, and the symbol of $W_{D}$ is the weight of dried hydrogels.

\subsection{Response surface methodology (RSM).}

MINITAB software (version 19) of the Response surface methodology (RSM) method was applied to evaluate the effects of cellulose concentration and ECH used on the swelling ratio and the reswelling kinetic of the hydrogels. The cellulose solution and ECH concentration were selected as effective factors, and the swelling ratio was selected as the response. 


\section{Results and Discussion}

\subsection{Surface morphology.}

Figure 1 (a)-(f) showed the SEM images of cellulose hydrogel synthesized from various concentrations of cellulose solution formed under both freezing and heating methods. All the cellulose hydrogels were observed to be highly porous. For cellulose hydrogel prepared from the highest concentration ( $5 \mathrm{w} / \%$ ) of the cellulose solution, the morphology of the resultant cellulose hydrogels was observed to be more compacted and less porous for both heating and freezing gelation methods. Whereas cellulose hydrogel prepared from the lowest cellulose concentration $(3 \mathrm{w} / \mathrm{v} \%)$ exhibited a more porous structure. The morphology of cellulose hydrogels synthesized under the heating gelation method was observed to be more porous.
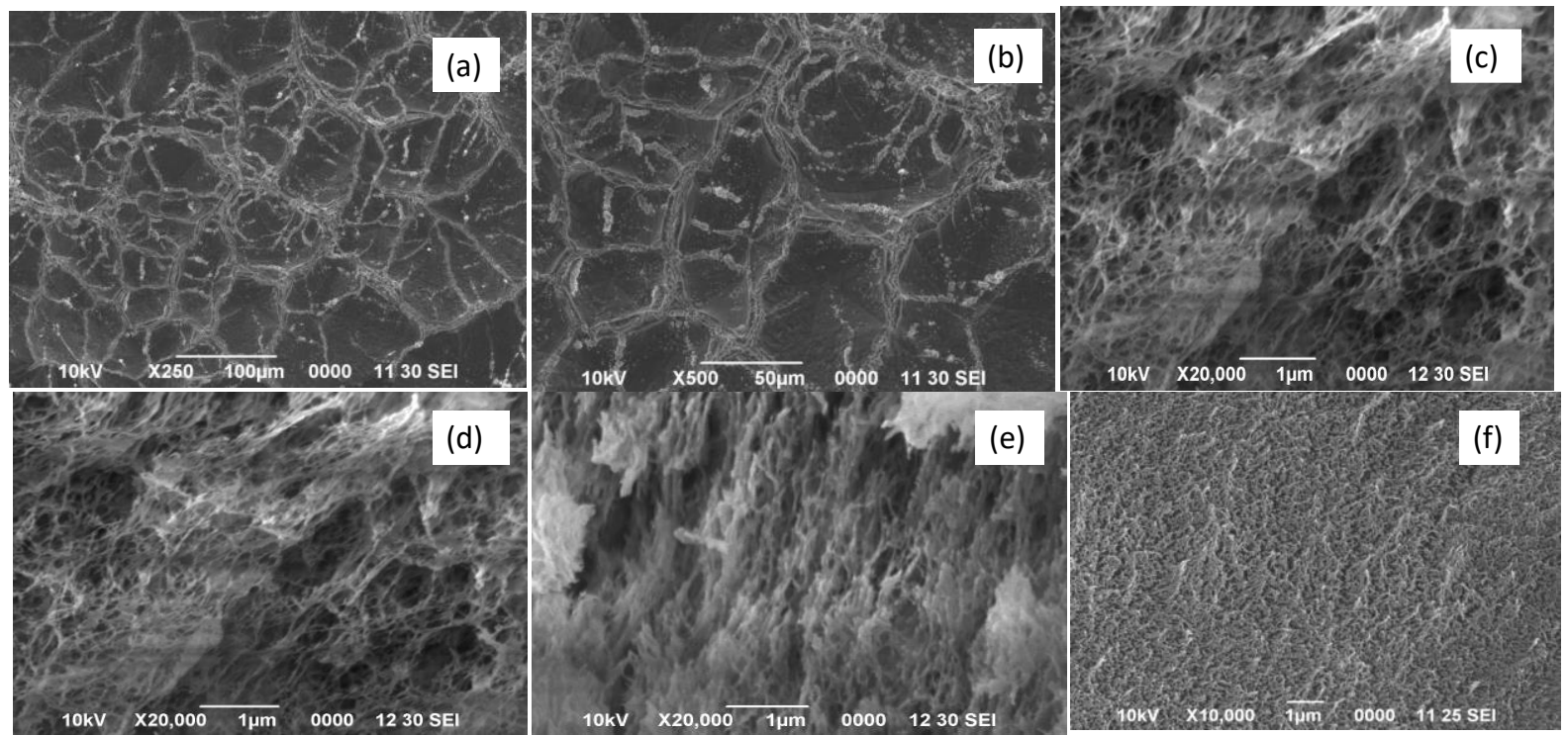

Figure 1. SEM images of cellulose hydrogel synthesized with (a) 3 (w/v\%), (b) 4 (w/v \%), (c) 5 (w/v\%) of cellulose solution under heating method; (d) $3(\mathrm{w} / \mathrm{v} \%)$, (e) $4(\mathrm{w} / \mathrm{v} \%)$, (f) $5(\mathrm{w} / \mathrm{v} \%)$ of cellulose solution under freezing method with $3 \%$ of $\mathrm{ECH}$ as a crosslinker

\subsection{Statistical optimization of the swelling ratio by Response Surface Methodology (RSM).}

3.2.1. The comparison of the swelling ratio based on the freezing method and the heating method.

There were 48 runs, and 33 runs were by Minitab 19 software to investigate the effects of the two variables (concentration of cellulose and ECH) under both freezing and heating gelation conditions on the swelling ratio of the cellulose hydrogel. The Pareto plots and the coded coefficient tables in Figure 3 and Table 1 predicted that the concentration of the cellulose solutions and the concentration of ECH have a significant effect on the swelling ratio by showing the p-value of less than 0.05. On the other hand, the p-values of the analysis of variance of the model under both gelation methods were also less than 0.05 , which indicated that it is statistically significant. The $R^{2}$ under both the freezing and heating methods are $88.61 \%$ and $90.19 \%$, respectively, and both values are close to each of their adjusted $R^{2}$ which are $87.25 \%$ and $88.38 \%$, respectively. The high $R^{2}$ value demonstrated that data fitted well in the model. The comparison of the concentration effects of the cellulose and ECH on the swelling ratio of hydrogels under both freezing and heating gelation conditions were shown in contour plots in Figure 2(a) and (b) and surface plots in Figure 4 (a) and (b), respectively. 
Both the contour plots in Figure 2(a) and (b) and the surface plots in Figure 4(a) and (b) predicted that the highest swelling ratio of $2250 \%$ could be achieved with $3(\mathrm{w} / \mathrm{v} \%)$ of the cellulose and $2.95 \%$ of the ECH under the freezing method and $2800 \%$ with 2.75 (w/v \%) of cellulose and $4.5 \%$ of ECH under the heating method.
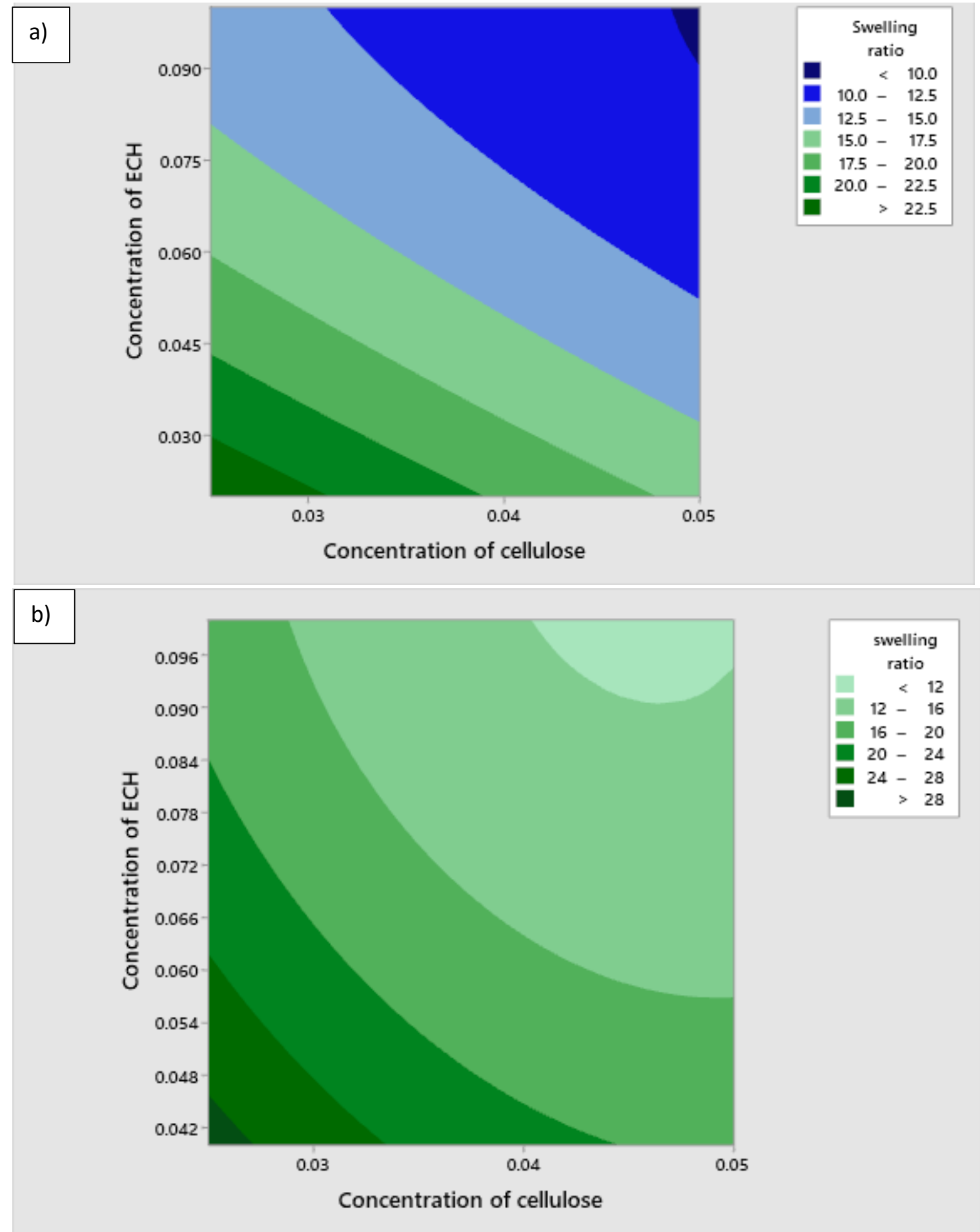

Figure 2. The contour plots of the swelling ratio of the cellulose hydrogels by (a) freezing method and (b) heating method.

Experiments were conducted to compare the results obtained with the results predicted using RSM. From the experimental result as presented in Figure 5(a) and (b), the maximum swelling ratios for cellulose hydrogels by the freezing method and the heating method were $2420.93 \%$ and $2467.72 \%$, respectively achieved by using cellulose concentration of $2.5 \mathrm{w} / \mathrm{v} \%$ and $4 \%$ (freezing method); $7 \%$ (heating method) of ECH. These experimental results were 
observed to be in good agreement with the results predicted from RSM of $2250 \%$ and $2800 \%$, respectively.

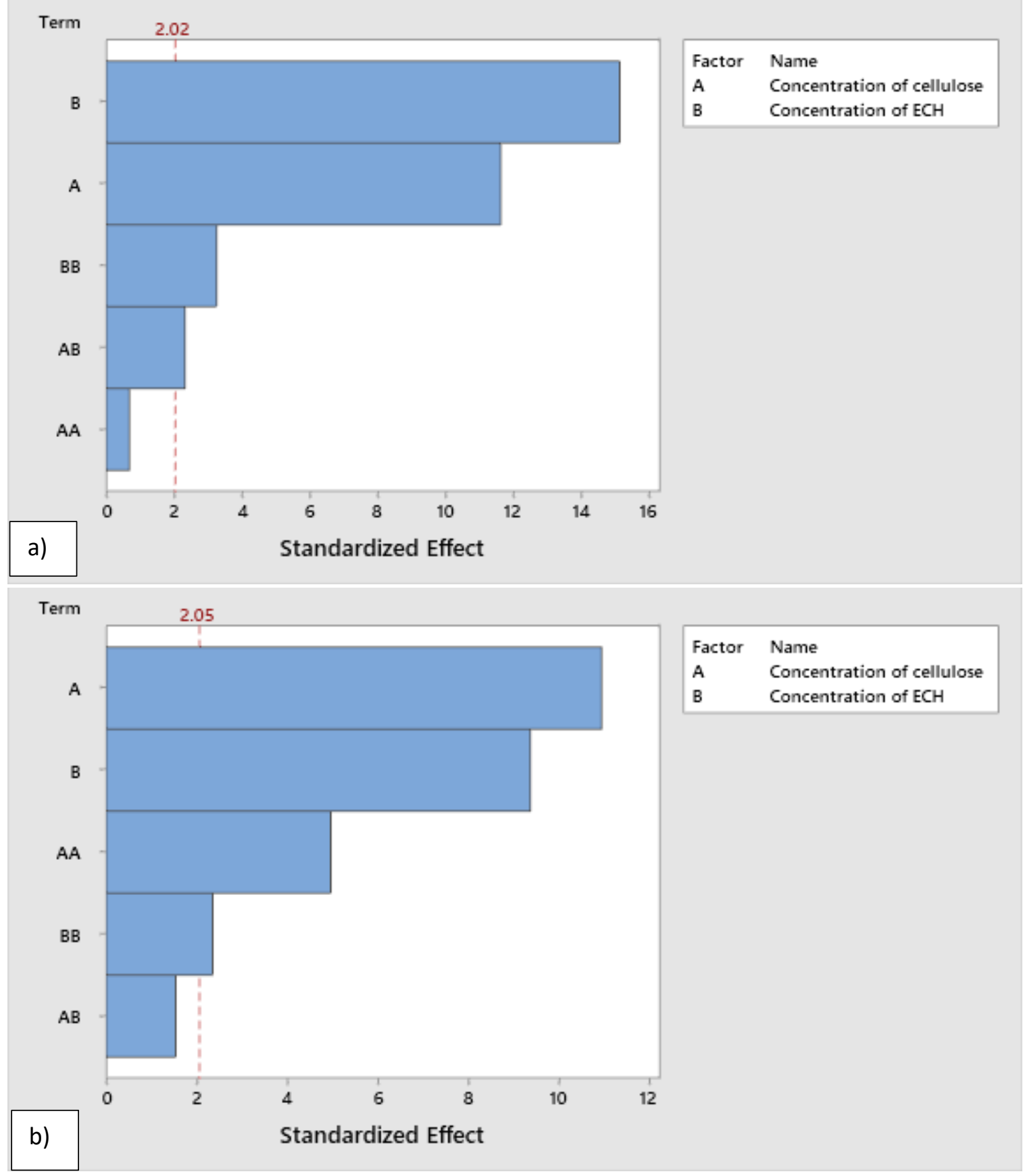

Figure 3. The Parto plots of the swelling ratio for (a) the freezing method for (b) the heating method.

Table 1. The coded coefficient tables for (a) the freezing method and (b) the heating method.

a)

\begin{tabular}{l|r|r|r|r} 
Term & Coef & SE Coef & T-Value & P-Value \\
\hline Constant & 14.328 & 0.285 & 50.26 & 0.000 \\
\hline Concentration of cellulose & -2.840 & 0.244 & -11.63 & 0.000 \\
\hline Concentration of ECH & -4.517 & 0.298 & -15.14 & 0.000 \\
\hline Concentration of cellulose*Concentration of cellulose & 0.263 & 0.386 & 0.68 & 0.499 \\
\hline Concentration of ECH*Concentration of ECH & 1.628 & 0.500 & 3.26 & 0.002 \\
\hline Concentration of cellulose*Concentration of ECH & 0.976 & 0.421 & 2.32 & 0.025 \\
\hline Term & VIF & & & \\
\hline Constant & & & & \\
\hline Concentration of cellulose & 1.19 & & & \\
\hline Concentration of ECH & 1.34 & & & \\
\hline Concentration of cellulose*Concentration of cellulose & 1.02 & & &
\end{tabular}




\begin{tabular}{|c|c|c|c|c|c|}
\hline \multirow{2}{*}{ b) } & Term & Coef & SE Coef & T-Value & P-Value \\
\hline & Constant & 15.743 & 0.334 & 47.20 & 0.000 \\
\hline & Concentration of cellulose & -4.139 & 0.378 & -10.94 & 0.000 \\
\hline & Concentration of ECH & -4.755 & 0.508 & -9.37 & 0.000 \\
\hline & Concentration of cellulose*Concentration of cellulose & 2.433 & 0.491 & 4.96 & 0.000 \\
\hline & Concentration of ECH*Concentration of ECH & 1.610 & 0.683 & 2.36 & 0.026 \\
\hline & Concentration of cellulose* Concentration of ECH & 0.959 & 0.624 & 1.54 & 0.136 \\
\hline & Term & \multicolumn{4}{|l|}{ VIF } \\
\hline & \multicolumn{5}{|l|}{ Constant } \\
\hline & Concentration of cellulose & 1.89 & & & \\
\hline & Concentration of ECH & 2.40 & & & \\
\hline & Concentration of cellulose* Concentration of cellulose & 1.12 & & & \\
\hline & Concentration of $\mathrm{ECH}^{*}$ Concentration of ECH & 1.80 & & & \\
\hline & Concentration of cellulose* Concentration of ECH & 2.05 & & & \\
\hline
\end{tabular}

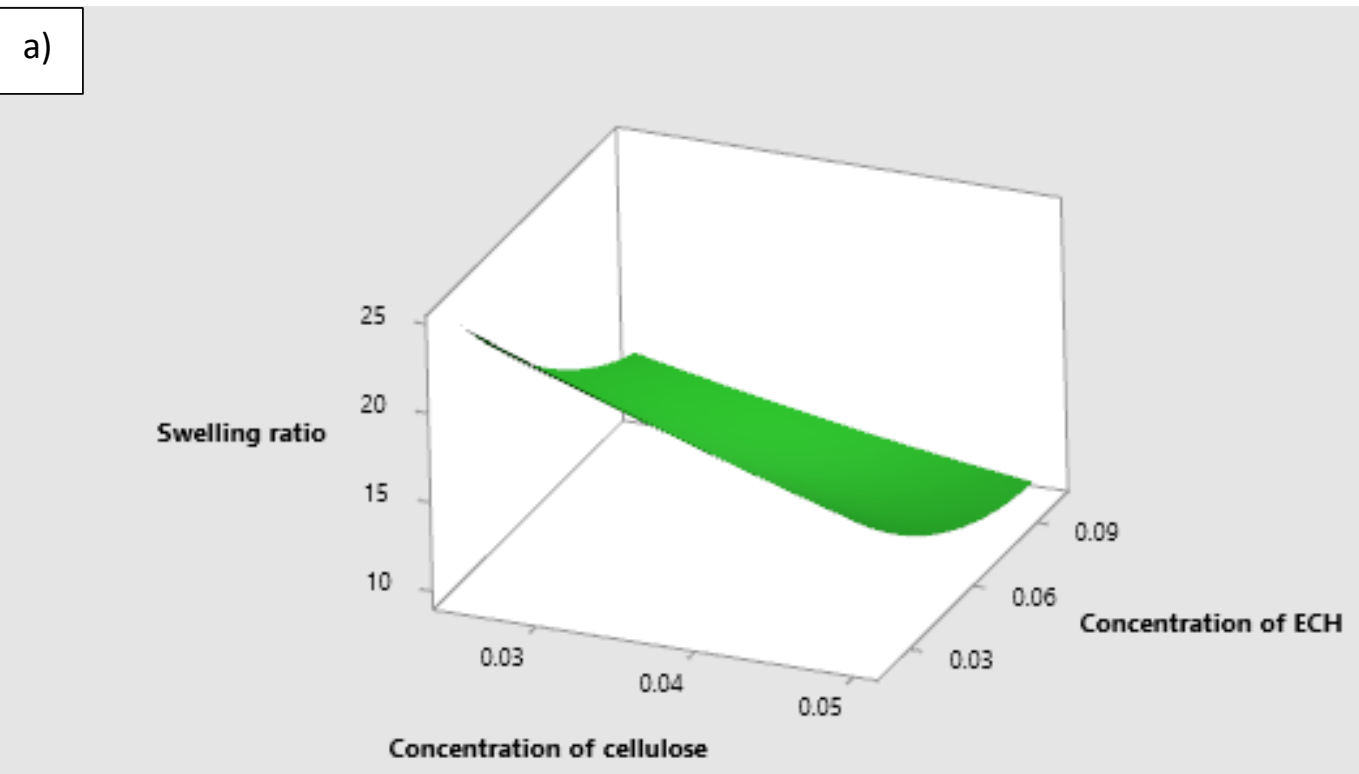

b)

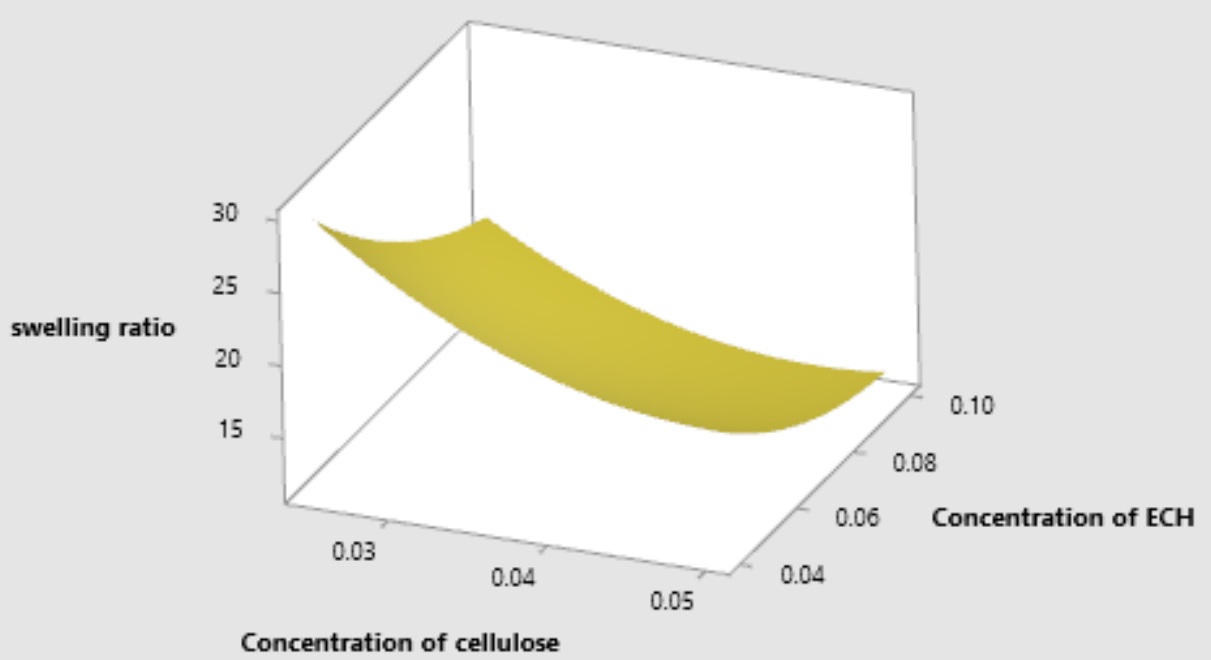

Figure 4. The surface plots of the swelling ratio versus the concentration of cellulose and ECH (a) by the freezing method and (b) by the heating method. 
Both the data optimized by RSM and experimental results showed that the swelling ratios were observed to decrease with the increased concentrations of both cellulose solutions under freezing and heating gelation conditions. As the cellulose concentration increased, the hydrogel networks became more compact, thus having limited expansion or stretching as the water molecules diffused into the networks [24,25]. The swelling capacity of the cellulose hydrogels was also observed to be restricted as a higher amount of ECH crosslinker was used. This was due to the cellulose polymer networks becoming more rigid due to a higher degree of crosslinking, and thus the hydrogel networks have limited expansion [26-28].

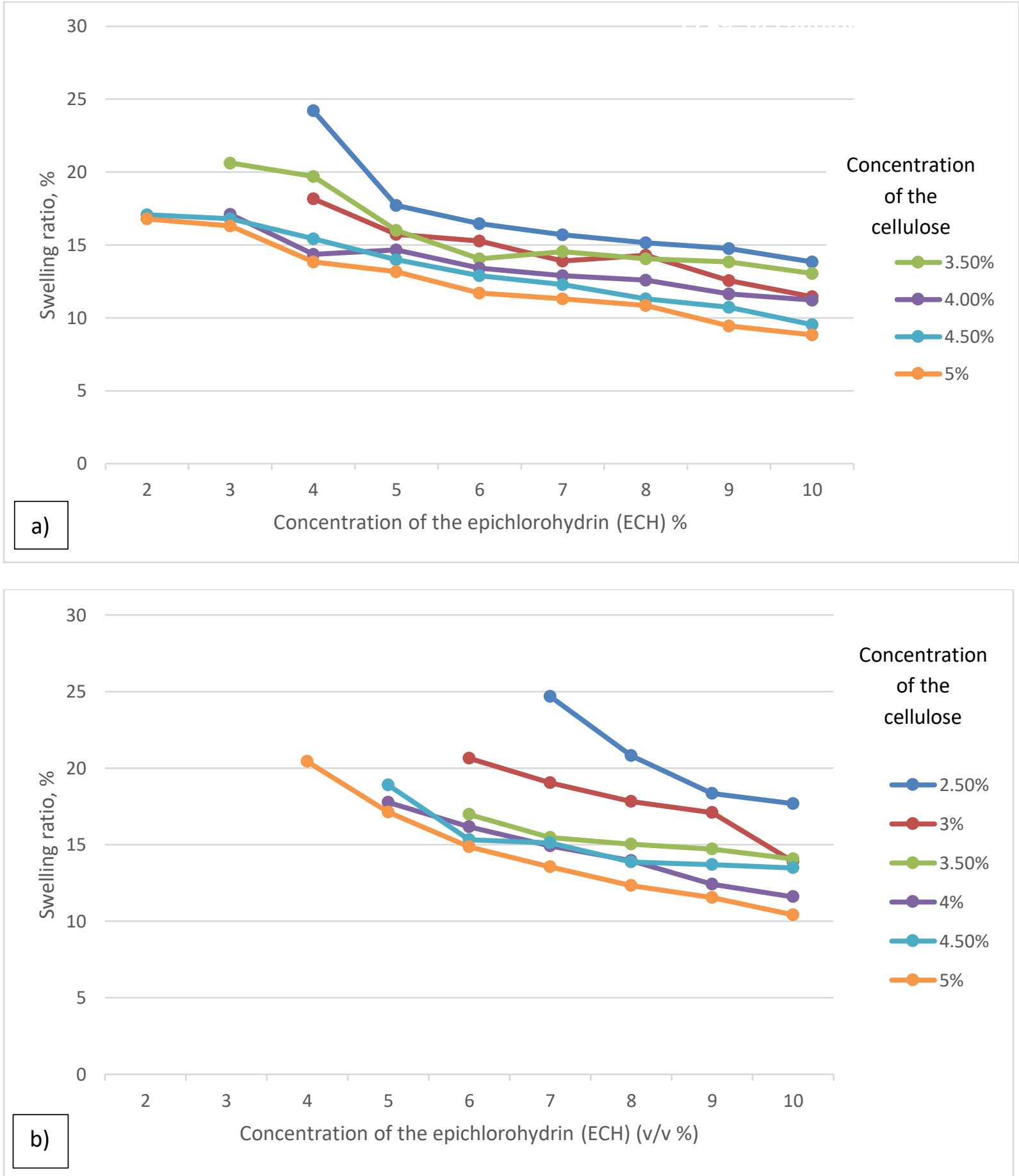

Figure 5. The experimental data of swelling ratio of cellulose hydrogel (a) by the freezing method and (b) by the heating method.

However, both the optimization by RSM (Figure 2 and Figure 4) and experimental results (Figure 5) showed that the heating gelation condition had produced cellulose hydrogel 
with a higher swelling property as compared to the freezing method. This is because the relatively denser and more rigid hydrogel structure prepared by the freezing method, as shown in SEM images (Figure 1 (d,e and f)), has limited penetration or absorbance of water into its network. Meanwhile, large pores observed in the hydrogel by the heating gelation method provided flexibility for the cellulose molecules to expand and allowed more penetration of water molecules [27, 29, 31]. At elevated temperatures, the heat provided kinetic energy to increase the mobility of cellulose polymer chains and caused the chains to entangle into a disordered structure randomly. Whereas for the freezing gelation method, low temperature caused slow molecular movement of polymer chains and resulted in forming a more ordered and denser structure $[30,32]$. So, the heating gelation method is more favorable for producing cellulose hydrogels with more porous morphology and a better swelling ratio.

\section{Conclusions}

Under optimum conditions, cellulose hydrogels with excellent swelling ratios of 2800 $\%$ have been successfully prepared from the cellulose fibers isolated from wastepapers. The optimum conditions predicted from RSM were 2.75 (w/v\%) of cellulose solution, $4.5 \%$ of ECH under heating gelation conditions. Both the concentrations of the cellulose and the crosslinkers $(\mathrm{ECH})$ and the gelation conditions have profound effects on the swelling ratios of the cellulose hydrogels. As these cellulose hydrogels demonstrate great water absorbency and are eco-friendly, biodegradable in nature, thus they hold great promise to be used as water reservoirs or controlled-release fertilizer carriers in sustainable horticulture and agriculture applications.

\section{Funding}

This research was funded by the International Foundation of Science (IFS), grant number GL/F07/IFS/2018 (agreement No:I-1-F-5207-2).

\section{Acknowledgments}

The financial support of the International Foundation of Science (IFS), grant number GL/F07/IFS/2018 (agreement No:I-1-F-5207-2), was greatly appreciated.

\section{Conflicts of Interest}

The authors declare no conflict of interest.

\section{References}

1. Jampi, A. L. W.; Chin, S. F.; Wasli, M. E.; Chia, C. H. Preparation of Cellulose Hydrogel from Sago Pith Waste as a Medium for Seed Germination. J. Phys. Sci. 2021, 32, 13-26, https://doi.org/10.21315/JPS2021.32.1.2.

2. Nie, J.; Pei, B.; Wang, Z.; Hu, Q. Construction of ordered structure in polysaccharide hydrogel: A review. Carbohydr. Polym. 2019, 205, 225-235, https://doi.org/10.1016/j.carbpol.2018.10.033.

3. Wei, P.; Chen, W.; Song, Q. et al. Superabsorbent hydrogels enhanced by quaternized tunicate cellulose nanocrystals with adjustable strength and swelling ratio. Cellul. 2021, 28, 3723-3732, https://doi.org/10.1007/s10570-021-03776-Z.

4. Tang, J.; Katashima, T.; Li, X., Mitsukami, Y.; Yokoyama, Y.; Sakumichi, N.; Chung, U.; Shibayama, M.; \& Sakai, T. Swelling Behaviors of Hydrogels with Alternating Neutral/Highly Charged Sequences. Macromolecules. 2020 53, 8244-8254, http://doi.org/10.1021/acs.macromol.0c01221.

5. Chin, S. F.; Jimmy, F, B.; Pang, S, C. Fabrication of cellulose aerogel from sugarcane bagasse as drug 
delivery carriers. J. Phys. Sci. 2016, 27, 159-168, http://dx.doi.org/10.21315/jps2016.27.3.10.

6. Yang, F.; Ma, J.; Bao, Y.; Zhu, Q.; Zhang, W. Swelling behaviors of super-absorbent hydrogel based waste: Bacteria Bran. J Polym Environ. 2021, 29, 1542-1550, https://doi.org/10.1007/s10924-020-01948-9.

7. Guan,Q. F.; Yang, H. B.; Han, Z. M.; Ling, Z. C.; Yin, C. H.; Yang, K. p.; Zhao, Y. X.; Yu, s. H. Sustainable $\begin{array}{llllll}\text { cellulose-nanofiber-based } \quad \text { hydrogels. } & \text { ACS } & \text { Nano. } & \text { 2021, }\end{array}$ http://doi.org/10.1021/acsnano.1c01247.

8. Salleh, K. M.; Zakaria, S.; Sajah, M, S.; Gan, S.; Chia, C. H.; Jaafar, S. N. S.; Amran, U. A. Chemically crosslinked hydrogel and its driving force towards superabsorbent behaviour. Int. J. Biol. Macromol. 2018, 118, 1422-1430, https://doi.org/10.1016/j.ijbiomac.2018.06.159.

9. Ho, B. K.; Chin, S. F.; Pang, S. C. pH-responsive carboxylic cellulose acetate nanoparticles for controlled release of penicillin G. J. Sci.: Adv. Mater. Devices. 2020, 5, 224-232, https://doi.org/10.1016/j.jsamd.2020.04.002.

10. Chin, S. F.; Romainor, A. N. B.; Pang, S.C. Fabrication of hydrophobic and magnetic cellulose aerogel with high oil absorption capacity. Mater. Lett. 2014, 115, 241-243, https://doi.org/10.1016/j.matlet.2013.10.061.

11. Pang, S. C.; Chin, S. F.; Yih, V. Conversion of cellulosic waste materials into nanostructured ceramics and nanocomposites. Adv. Mater. Lett. 2011, 2, 118-124, https://doi.org/10.5185/amlett.2011.1203.

12. Chin, S.F.; Romaninor, A. N. B.; Pang, S. C.; Lihan, S. Antimicrobial starch-citrate hydrogel for potential applications as drug delivery carriers. J Drug Deliv Sci Technol. 2019, 54, 101239, https://doi.org/10.1016/j.jddst.2019.101239.

13. Fan, X.; Yang, L.; Wang, T.; Sun, T.; Lu, S. pH-responsive cellulose-based dual drugloaded hydrogel for wound dressing, Eur. Polym. J. 2019. https://doi.org/10.1016/j.eurpolymj.2019.109290.

14. Lin, P. J.; Liu, L. L.; He, G. H.; Zhang, T.; Yang, M.; Cai, J. Z.; Fan, L. H.; Tao, S. X. Preparation and properties of carboxymethyl chitosan/oxidized hydroxyethyl cellulose hydrogel. Int. J. Biol. Macromol. 2020. 162, 1692-1698, https://doi.org/10.1016/j.ijbiomac.2020.07.282.

15. Wei, Z.; Wu, C.; Li, R.; Yu, D.; Ding, Q. Nanocellulose based hydrogel or aerogel scaffolds for tissue engineering. Cellul. 2021, 28, 7497-7520, https://doi.org/10.1007/s10570-021-04021-3.

16. Calcagnile, P.; Sibillano, T.; Giannini, C.; Sannino, A.; Demitri, C. Biodegradable poly(lactic acid)/cellulosebased superabsorbent hydrogel composite material as water and fertilizer reservoir in agricultural applications. J Appl Polym Sci. 2019, 136, 47546, https://doi.org/10.1002/app.47546.

17. Michalik, R.; Wandzik, I. A Mini-Review on Chitosan-Based Hydrogels with Potential for Sustainable Agricultural Applications. Polymers 2020, 12, 2425, https://doi.org/10.3390/polym12102425.

18. Mali, K. K.; Dhawale, S. C.; Dias, R. J. Synthesis and characterization of hydrogel films of carboxymethyl tamarind gum using citric acid. Int. J. Biol. Macromol. 2017, 105, 463-470, https://doi.org/10.1016/j.ijbiomac.2017.07.058.

19. Voon, L. K.; Pang, S. C.; Chin, S. F. Optimizing Delivery Characteristics of Curcumin as a Model Drug via Tailoring Mean Diameter Ranges of Cellulose Beads. Int. J. Polym. Sci. 2017a. https://doi.org/10.1155/2017/2581767.

20. Voon, L. K.; Pang, S. C.; Chin, S. F. Porous Cellulose Beads Fabricated from Regenerated Cellulose as Potential Drug Delivery Carriers. J. Chem. 2017b, 2017, https://doi.org/10.1155/2017/1943432.

21. Voon, L. K.; Pang, S, C.; Chin, S. F. Highly porous cellulose beads of controllable sizes derived from regenerated cellulose of printed paper wastes. Mater. Lett. 2016, 164, 264-266, https://doi.org/10.1016/j.matlet.2015.10.161.

22. Chin, S. F.; Pang, S. C.; Tay, S. H. Size controlled synthesis of starch nanoparticles by a simple nanoprecipitation method. Carbohydr. Polym. 2011, 86, 1817-1819, https://doi.org/10.1016/j.carbpol.2011.07.012.

23. Chang, C.; Zhang, L.; Zhou, J.; Zhang, L.; Kennedy, J. F. Structure and properties of hydrogels prepared from cellulose in $\mathrm{NaOH} / \mathrm{urea}$ aqueous solutions. Carbohydr. Polym. 2010, 82, 122-127, https://doi.org/10.1016/j.carbpol.2010.04.033.

24. Alonso, G. J.; Rivera, J. L. A.; Mendoza, A. M. M.; Mendez, M. L. H. Effect of temperature and pH on swelling behavior of hydroxyethyl cellullose-acrylamide hydrogel. E-Polymers. 2014, 7, https://doi.org/10.1515/epoly.2007.7.1.1744.

25. Pang, S. C.; Chin, S. F.; Tay, S. H.; Tchong, F. M. Starch-maleate-polyvinly alcohol hydrogels with controllable swelling behaviours. Carbohydr. Polym. 2010, 84, 424-429, https://doi.org/10.1016/j.carbpol.2010.12.002.

26. Zainal, S. H.; Mohd, N. H.; Suhaili, N.; Anuar, F. H.; Lazim, A. M.; Othaman, R. Preparation of cellulosebased hydrogel: A review. J. Mater. Res. Technol. 2021, 10, 935-952, https://doi.org/10.1016/j.jmrt.2020.12.012.

27. Alam, M. N.; Christopher, L. P. Natural Cellulose-Chitosan Cross-Linked Superabsorbent Hydrogels with Superior Swelling Properties. ACS Sustain. Chem. Eng. 2018, 6, 8736-8742, https://doi.org/10.1021/acssuschemeng.8b01062.

28. Shin, J-Y.; Lee, D.Y.; Kim, B-Y.; Yoon, J.I. Effect of polyethylene glycol molecular weight on cell growth behavior of polyvinyl alcohol/carboxymethyl cellulose/polyethylene glycol hydrogel. J Appl Polym Sci. 2020, 137, e49568, https://doi.org/10.1002/app.49568. 
29. Liu, C.; Zhang, H. J.; You, X.; Cui, K.; Wang, X. Electrically Conductive Tough Gelatin Hydrogel. Adv. Electron. Mater. 2020, 6, 2000040, https://doi.org/10.1002/aelm.202000040.

30. Yang, J.; Bai, R.; Chen, B.; Suo, Z. Hydrogel Adhesion: A Supramolecular Synergy of Chemistry, Topology, and Mechanics. Adv. Funct. Mater. 2020, 30, 1901693, https://doi.org/10.1002/adfm.201901693.

31. Culebras,M.; Barrett, A.; Pishnamazi, M.; Walker, G. M.; Collins, M. Wood-Derived Hydrogels as a Platform for Drug-Release System. ACS Sustain. Chem. Eng. 2021, 9, 2515-2522, https://doi.org/10.1021/acssuschemeng.0c08022.

32. Palantöken, S.; Bethke, K.; Zivanovic, V.; Kalinka, G.; Kneipp, J.; Rademann, K. Cellulose hydrogels physically crosslinked by glycine: Synthesis, characterization, thermal and mechanical properties. J. Appl. Polym. Sci. 2020, 137, 48380, https://doi.org/10.1002/app.48380. 